RESEARCH PAPER

J. Food Sci. Technol. Nepal, Vol. 8 (30-34) 2013

ISSN: 1816-0727

\title{
Microbial Quality of Selected Commercial Fresh Fruit Juices Sold in Mysore City
}

\author{
DIVYASHREE S., JAMUNA PRAKASH and PRABAHAVATHIS.N. \\ Department of Studies in Food Science and Nutrition, University of Mysore, Manasagangotri,Mysore-570 006, India
}

*Corresponding author: jampr55@hotmail.com

Fruit juices are common man's beverages and sold at public places. Since they are known for carrying heavy microbial load, the present investigation was undertaken to enumerate and identify the microorganisms in fruit juices (sweet lime, orange and pineapple) selected from three different street vended shops (source A, B and C) in Mysore. The juices were analyzed for the microbial quality for type of organisms and number of colonies by serial dilution technique, pour plate method,gram's staining method and staining for fungi; and physico-chemical properties. Results showed that the pineapple juice from two sources was highly contaminated with bacterial pathogens $\left(25 \times 10^{4} \mathrm{CFU} / \mathrm{mland} 20 \times 10^{4} \mathrm{CFU} / \mathrm{ml}\right)$. All samples were contaminated with faecal streptococci. In source- $B$ and $C$, all juices showed high counts of fungal colonies (Aspergillus, Penicillium, Fusarium and yeast). It is contended that contamination was mainly due to poor quality of water used for dilution as well as prevailing unhygienic conditions related to washing of utensils and maintenance of the premises. The result showed the poor hygienic quality of street vended fruit juices and the possible risk to the consumers.

Keywords:Physico-chemical properties, morphological characterization, microbial load, sweet lime, orange, pineapple

\section{Introduction}

Fruit juice is defined as a "non-fermented and nonsparkling fruit or vegetable beverage, obtained by the dilution in potable water of the juice, pulp or vegetable extract of the fruit of origin, with or without sugar" (Piló et al., 2009). These are the unfermented, but fermentable, liquids obtained from the edible part of sound, appropriately mature and fresh fruits or fruits maintained in fresh condition by physical means or other suitable treatments. Juices can be obtained by mechanical extraction processes or by reconstitution of concentrated fruit juice with clean water. Juices can be cloudy or clear and have the essential characteristics typical of the juice of the fruit from which it comes. Diluting and/or blending are common practices as many fruit juices are either too acid or too strongly flavored to be pleasant for consumption. Fruit juice drinks typically contain no less than $20 \%$ fruit juice. Fruit juices are becoming an important part of the modern diet in many communities (Ghenghesh et al., 2005). In some studies, fruit and juice intake was found to be associated with higher dietary status index in rural women (Knol and Haughton, 1998 andGhenghesh et al., 2005).

Fruit juices are well recognized for their nutritive value, especially mineral, and vitamin content. In many tropical countries they are common man's beverages and are sold at all public places and roadside shops (Lewis et al., 2006). These juices provide a source of readily available and affordable source of nutrients to many sectors of the population, including the urban poor. Unpasteurized juices are preferred by the consumers because of the "fresh flavor" attributes and hence, in recent times, their demand has increased. They are simply prepared by extracting, usually by mechanical means, the liquid and pulp of mature fruit and vegetables. The final product is an unfermented, clouded, untreated juice, ready for consumption. However, in view of their ready consumption, quick methods of cleaning, handling and extraction; they could often prove to be a public health threat (Parish, 2009). There are reports of food borne illnesses associated with the consumption of fruit juices at several places in India and elsewhere (Ahmed et al., 2009; Olorunjuwon et al., 2014; Sandeep et al., 2001; Sharma, 2013). Hence with this background, the present study was undertaken to analyze fresh fruit juice samples selected from three different food vendors sold in Mysore city for physico-chemical and microbial quality. This was expected to throw light on safety of street vended foods. 


\section{Divyashree et al.: J. Food Sci. Technol. Nepal, Vol. 8 (30-34 ), 2013}

\section{Materials and Methods} Collection of samples

Threeroadside shops located at distance of $3.0 \mathrm{~km}$ from each other in central part of Mysore city were chosen for collection of samples. Three varieties of fresh fruit juices namely orange, sweet lime and pineapple were chosen, as these are most popular beverages. All samples were collected in sterile containers as sold to consumers, held at $4^{\circ} \mathrm{C}$ and analyzed within an hour after procurement.

\section{Physical and chemical analysis}

The physical and chemical parameters were determined by standard techniques (Ranganna, 2007) and comprised of following assays:measurement of $\mathrm{pH}$ with a $\mathrm{pH}$ meter, (H $12211 \mathrm{pH}$ meter/ORP meter), total titratable acidity by titration with $0.1 \mathrm{~N}$ sodium hydroxide solution (results expressed in grams citric acid per $100 \mathrm{~mL}$ of sample) and quantity of total soluble solids ( ${ }^{\circ}$ Brix) with a Brix refractometer and total solids. All assays were performed in triplicate.

\section{Microbial analysis}

For microbial analysis, $1.0 \mathrm{~mL}$ of fresh juice was diluted with $10 \mathrm{~mL}$ of saline solution and filtered through sterile Whatman No.1 filter paper to remove solid particles. 1.0 $\mathrm{mL}$ of filtrate was used for inoculation. Juice samples were serially diluted in saline, and incubated at $37^{\circ} \mathrm{C}$ for 24 hours.Isolation and enumeration of bacteria and fungi were made using the growth in selective media such as nutrient agar and potato dextrose agar for total plate count. In this study, three samples were collected from each location and surface plates were made in triplicates in appropriate selective media. Bacterial isolation was performed by pour plate method and serial dilution technique. For bacterial enumeration colony forming units (CFU) was used. For computation, average number per plate was divided by sample volume and is expressed as $\mathrm{CFU} / 100 \mathrm{~mL}$ (AOAC, 2005).

\section{Statistical analysis}

The results of the study were compiled for obtaining mean and standard deviation. Analysis of variance was used for determining significant differences between samples.

Table 1. Physico-chemical parameters of fruit juices collected from different sources

\begin{tabular}{cccccc}
\hline Source & Fruit juice & $\mathbf{p H}$ & ${ }^{\circ}$ Brix value & Acidity \% & Total solids \% \\
\hline $\mathbf{A}$ & Sweet lime juice & 3.75 & 10 & $0.22 \pm 0$ & $13.36 \pm 0.33$ \\
& Orange juice & 3.36 & 7.5 & $0.25 \pm 0$ & $14.96 \pm 0.47$ \\
& Pineapple juice & 3.40 & 7 & $0.46 \pm 0.1$ & $14.16 \pm 0.23$ \\
$\mathbf{B}$ & Sweet lime juice & 3.85 & 8.8 & $2.8 \pm 0.01$ & $16.19 \pm 0.47$ \\
& Orange juice & 3.72 & 7.3 & $0.39 \pm 0.03$ & $18.26 \pm 0.28$ \\
& Pineapple juice & 3.32 & 8 & $0.15 \pm 0$ & $15.75 \pm 1.34$ \\
$\mathbf{C}$ & Sweet lime juice & 3.58 & 7 & $0.14 \pm 0.01$ & $15.98 \pm 0.26$ \\
& Orange juice & 3.44 & 8 & $0.31 \pm 0.01$ & $13.65 \pm 0.49$ \\
& Pineapple juice & 3.45 & 5 & $2.95 \pm 0.05$ & $10.92 \pm 1.44$
\end{tabular}

\section{Results and Discussion}

The physico-chemical characteristics of fruit juice samples are shown in Table 1.

The $\mathrm{pH}$ values of the sweet lime juice varied from 3.583.85 , while for the orange juice, the levels ranged from 3.36 to 3.72 and for the pineapple juice, it was found to be in the range of 3.32-3.45.The survival and growth of food borne pathogens seen on the surfaces of fruits shows that some pathogens may survive in fruit juices having low $\mathrm{pH}$. The low $\mathrm{pH}$ of fruit juices leads to yeast growth (Pilo et al., 2009). Due to low pH of pineapple juice it was observed that it had higher microbial load as compared to other fruit juices. In a study it is reported that the $\mathrm{pH}$ of pineapple juice and sweet lime juice was $<3.0$, which is acidic (Titarmare et al., 2009). Ethiopian authors reported that the pineapple juice had a $\mathrm{pH}$ of 4.00 (Ketema, 2008). In another study by Pilo et al. (2009),orange flavored juices were reported to have $\mathrm{pH}$ levels ranging from 2.72 to 3.14 .

In the present study in relation to total soluble solids, ${ }^{\circ}$ Brix value was also measured and it varied from 5 to $10^{\circ} \mathrm{Brix}$ in all the fruit juices. The Brix value of the sweet lime juice varied from 7 to $10^{\circ}$ Brix, for orange juice it was in the range of 7.3 to $8^{\circ} \mathrm{Brix}$, and for the pineapple juice, from 5 to $8{ }^{\circ}$ Brix. Pilo et al. (2009) reported 


\section{Divyashree et al.: J. Food Sci. Technol. Nepal, Vol. 8 (30-34 ), 2013}

a range of total soluble solids from 0.5 to $5{ }^{\circ}$ Brix for powdered orange flavored juices. The high percentage of total soluble solids ( ${ }^{\circ}$ Brix) found might possibly be due to the addition of excess sugar to the fruit juices. Sweet lime juice had high ${ }^{0}$ Brix value than the other juices. Added sugar also becomes an added factor to promote the growth of organisms as sugar provides ready energy for growth. Parish and Higgins (1989) reported that yeasts are generally involved in the deterioration of fruit juices; because they tolerate high sugar concentration and low $\mathrm{pH}$, these factors favor their growth.

The titratable acidity level and total solids of selected fruit juices are also given in Table 1 . The titratable acidity also showed considerable variation among the analyzed samples. The titratable acidity of sweet lime juice varied from 0.14 to $2.8 \%$, for orange juice the values varied from 0.25 to $0.39 \%$ and for pineapple juice, it was 0.15 to $2.95 \%$. As per the Fruit Products Order specification, acidity expressed as anhydrous citric acid in fruit juices, should not be more than $3.5 \%$. The titratable acidity of the above samples did not exceed $3.5 \%$. Pilo et al. (2009) reported that the titratable acidity of orange juice samples varied from 0.40 to $1.40 \mathrm{~g} / \mathrm{mL}$. In our study, the orange juice was shown to have acidity value within the range of $0.25 \%$ to $0.39 \%$. The amount of total solids in sweet lime juice ranged from 13.36 to $16.19 \%$, for orange juice, the values varied from 14.96 to $18.26 \%$, the orange and sweet lime juice contained more pulp which adds up to the solid content and it was found to be high in one sample i.e., $18.26 \%$ as compared to other samples. The total solids in pineapple juice was found to be in the range of 10.92 to $15.75 \%$ as this also containedpart of pulp and in some shops the eye of the pineapple fruit was not removed, hence it added up to the weight of total solids.

The fruit juice samples were analyzed for bacterial pathogens and their morphological characteristics were observed under the microscope. The characteristics of the

Table 2. Morphological characterization of bacterial isolates from the fruit juices samples

\begin{tabular}{lll}
\hline Fruit juice & Colony color, elevation and edge & Identified organisms \\
\hline Sweet lime juice & Creamy, filamentous & Micrococcus sp \\
& Flat, filamentous & Streptococcus \\
& Raised, entire & Staphylococcus \\
& Creamy, filamentous & Cocci \\
Creamy, regular & Bacillus \\
Orange juice & creamy, raised & Streptococcus \\
& Raised, regular & Micrococcus sp \\
& Raised, entire & Cocci \\
& Creamy, entire & Staphylococcus \\
Cineapple juice & Creamy, regular & Bacillus \\
& Creamy, regular & Streptococcus \\
& Creamy, raised & Staphylococcus \\
& Raised, entire & Cocci \\
\hline
\end{tabular}

organisms identified are shown in Table 2. Commonly observed organisms were Micrococcus spp, Bacillus, Streptococcus, Staphylococcus spp.

Sweet lime juice: Sweet lime juice was enumerated for its bacterial colonies as indicated in Table 3 . The colonies were found to be in the range of $7.3 \times 10^{3}$ and $23 \times 10^{3}$ per $100 \mathrm{~mL}$ of the juice in $10^{-1}$ dilution. Source A had the highest and lowest dilution ranging between $12 \times 10^{4}$ $-23 \times 10^{3}$. Source B had the highest and lowest dilution

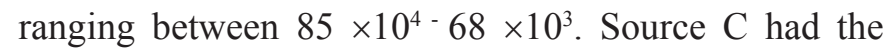

highest and lowest dilution ranging between $19 \times 10^{4-77}$ $\times 10^{3}$. A study conducted in Amaravati city showed that sweet lime juice had 17 bacterial pathogens, which could be isolated and identified, it was reported that the juice was highly contaminated with E. coli (41\%) (Tambekar et al., 2009).

Orange juice: The number of colonies in source A was in the range of $15 \times 10^{4}-7 \times 10^{3}$. Source B had the colonies ranging between $9.6 \times 10^{4}-1 \times 10^{3}$, whilesource $\mathrm{C}$ had the colonies ranging between $15 \times 10^{4}-5 \times 10^{3}$. 
Divyashree et al.: J. Food Sci. Technol. Nepal, Vol. 8 (30-34 ), 2013

The microbial load in orange juice was reported as 1-5 $\log$ CFU/mL (Parish et al. 1997, Parish 1998, Andres et al. 2001, Pao et al, 2001). In Tripoli-Libya Ghenghesh et al. (2005) reported that 19 samples of orange juice had total viable count of $<1-1.1 \times 10^{5}$, and a mean of $2.4 \times 10^{4}$ for total viable count.

Pineapple juice: In pineapple juice from source $A$ the colonies were found to be $25 \times 10^{4}$. Source B had the col- onies ranging between $19 \times 10^{4}-2 \times 10^{3}$ and Source $\mathrm{C}$ had the colonies ranging between $20 \times 10^{4}-11 \times 10^{3}$. Ghenghesh et al. (2005) reported that pineapple juice had a total viable count of $3.5 \times 10^{4} \mathrm{CFU} / \mathrm{mL}$. Study conducted in Vishakhapatnam city by Lewis et al. (2006) reported that in pineapple juice the total viable count was $18.8 \times 10^{4}$ $\mathrm{CFU} / \mathrm{mL}$ and it had total coliforms ranging from 11.4 to $22.4 \times 10^{4} \mathrm{CFU} / \mathrm{mL}$, which indicates a very high contamination by coliforms. As compared to the values of

Table 3.Number of colonies per $100 \mathrm{~mL}$ of the sample

\begin{tabular}{|c|c|c|c|c|c|}
\hline \multirow[t]{2}{*}{ Type of juice } & \multirow[t]{2}{*}{ Source } & \multicolumn{2}{|c|}{ Colonies per $100 \mathrm{~mL}$} & \multicolumn{2}{|c|}{ Statistical analysis } \\
\hline & & Highest dilution & Lowest dilution & FRatio & P-Value \\
\hline \multirow[t]{3}{*}{ Sweet lime juice } & $\mathbf{A}$ & $12 \times 10^{4}$ & $23 \times 10^{3}$ & 21.24 & $0.001894^{* *}$ \\
\hline & B & $19 \times 10^{4}$ & $7.7 \times 10^{3}$ & & \\
\hline & $\mathbf{C}$ & $8.5 \times 10^{4}$ & $6.8 \times 10^{3}$ & & \\
\hline \multirow[t]{3}{*}{ Orange juice } & $\mathbf{A}$ & $15 \times 10^{4}$ & $7 \times 10^{3}$ & 1.99 & $0.21664^{\mathrm{ns}}$ \\
\hline & B & $9.6 \times 10^{4}$ & $1 \times 10^{3}$ & & \\
\hline & $\mathrm{C}$ & $15 \times 10^{4}$ & $5 \times 10^{3}$ & & \\
\hline \multirow[t]{3}{*}{ Pineapple juice } & $\mathbf{A}$ & $19 \times 10^{4}$ & $2 \times 10^{3}$ & 3.16 & $0.114978^{\mathrm{ns}}$ \\
\hline & B & $25 \times 10^{4}$ & $7.3 \times 10^{3}$ & & \\
\hline & $\mathbf{C}$ & $20 \times 10^{4}$ & $11 \times 10^{3}$ & & \\
\hline
\end{tabular}

Vishakhapatnam study the total viable count of the present study was also $20.8 \times 10^{4} \mathrm{CFU} / \mathrm{mL}$ which is considered to be very high.

\section{Identification of fungi}

Sweet lime juice: Source A was found to have organisms such as, Aspergillus and Penicillium spp., a dense growth of black colored colonies, and blue colored colonies were observed in this sample and in some petridishes the colonies could not be differentiated due to their dense growth, especially in Aspergillus colonies. In source B along with Penicillium andAspergillus, Rhizopus was identified, which is a common spoilage organism. In source CAspergillus, Penicillium and Fusarium were identified. By this we can infer that sweet lime juice had more of Aspergillus and Penicillium in all the three sources.

Orange juice:The organisms identified in orange juice were Penicillium, yeast and Fusarium, in source A,Penicillium, and in source C,Aspergillus, Penicillium and more of yeast colonies were observed which could be due to the fermentation of the juice. Source A juice did not show much of fungal colonies. Source $\mathrm{C}$ juice was highly contaminated with fungal spores in comparison to the other two sources.

Pineapple juice: In source A, only Aspergillus was identified. In source B and source C, Aspergillus, Penicillium and yeasts were identified. From the above results, it can be inferred that source $\mathrm{B}$ and source $\mathrm{C}$ (sweet lime, orange and pineapple juice) juices showed high counts of fungal colonies (Aspergillus, Penicillium, Fusarium and yeast). Pilo et al. (2009) reported that yeast colonies in orange juice were found to present in the range of $1 \times 10^{2}-9.35 \times 10^{4} \mathrm{CFU} / \mathrm{mL}$ of yeasts in 20 samples. In a study Al-jedahand Robinson(2002) reported that pineapple juice has total viable count of 1.5 $\times 10^{5}$. Highly significant differences werefound in colony count of sweet lime juice from three sources with $p$ value of 0.001894 on application of ANOVA.

\section{Conclusions}

From this study it can be concluded that source A and C pineapple juices had high microbial load in comparison to other samples. All the fruit juices from all the sources were contaminated and pineapple juice was highly contaminated. It is contended that contamination is mainly due to poor quality of water used for dilution as well as prevailing unhygienic conditions related to washing of utensils and maintenance of the premises. The results in the present study shows that source clearly indicates the poor hygienic conditions of these juices 
Divyashree et al.: J. Food Sci. Technol. Nepal, Vol. 8 (30-34 ), 2013

and the consumers are at risk of contacting food borne infections. Hence an awareness program regarding the maintenance of hygiene and sanitation in preparing and serving of juices should be imparted for vendors especially for the street juice vendors.

\section{References}

Ahmed M.S.U.,Nasreen T.,Feroza B. and Parveen S. (2009). Microbiological quality of local market vended freshly squeezed fruit juices in Dhaka city, Bangladesh. Bangladesh Journal of Scientific and Industrial Research, 44(4), 421-429.

Al-Jedah J.H. and Robinson R.K. (2002). Nutritional value and microbiological safety of fresh fruit juices sold through retail outlets in Qatar. Pakistan Journal of Nutrition, 1 (2): 79-81.

Andres S.C., Giannuzzi L. and Zaritzky N.E.(2001). Mathematical modeling of microbial growth in packaged refrigerated orange juice treated with chemical preservatives. Journal of Food Science, 66(5): 724-728.

AOAC (2005). FDA Bacteriological Analytical Manual, 18th edn, Washington, DC.

Ghenghesh K.S., Belhaj K., El-Amin W.B., Nefathi E.andZalmum A. (2005). Microbiological quality of fruit juices sold in Tripoli-Libya. Food Control Journal, 16: 855-858

Ketema J.( 2008). On normalization of infinitely combinatory reduction systems, Springer, 172186, ISSN: 0302-9743.

Knol L.L. and Haughton B.(1998). Fruit and juice intake associated with higher dietary status index in rural East. Journal of The American Dietetic Association. 98: 73.

Lewis J.E., Thompson P., Rao N. Kalavati C. and Rajanna B. (2006). Human bacteria in street vended fruit juices: A case study of Visakhapatnam City, India. Internet Journal of Food Safety, $8: 35-38$.

Olorunjuwon B.O., Temitope B.K., Muibat F.O. and Afolabi O. (2014). Microbiological quality of some locally produced fruit juices in Ogun state, South Western Nigeria. Journal of Microbiology Research, 2(1), 1-8.

Parish M.E. and Higgins D.P. (1989). Yeasts and moulds isolated from spoiling citrus products. Journal of Food Protection, 52: 261-263.
Parish M.E. (1997). Public health and non-pasteurized fruit juices. Critical Reviews in Microbiology, 23(2): 109-119.

Parish M.E. (1998). High pressure inactivation of saccharomyces cerevisiae endogenous microflora and pectinmethylesterase in orange juice. Journal of Food Safety, 18(1): 57-65.

Parish M.E., (2009). Food safety issues and the microbiology of fruit beverages and bottled water. In: Microbiologically Safe Foods. Heredia, N., Wesley, I. and Garcia, S. (Eds) John Wiley \& Sons: 291-303.

Pao S., Davis C., Craig L., Parish M.E. and Mickey E. (2001).Microscopic observation and processing validation of fruit sanitizing treatments for the enhanced microbiological safety of fresh orange juice. Journal of Food Protection, 3: 310314.

Piló F.B., Pereira N.O., Freitas D., Miranda N.D., Carmo S.D., Gomes C.O., Nardi M.D. and Rosa C.A. (2009). Microbiological testing and physical and chemical analysis of reconstituted fruit juices and coconut water. Journal of Alimentaria Nutria, 20(4): 523-532.

Ranganna S. (2007) Handbook of Analysis and Quality Control of Fruits and vegetables Products, $2^{\text {nd }}$ Edn. Tata McGraw Hill Publishing Co.Ltd. New Delhi.

Sandeep M., Diwakar A. and Abhitjit G. (2001). Microbiological analysis of street vended fresh squeezed carrot and kinnow-mandarian juices in Patiala city, India. Internet Journal of Food Safety, 3: 1-3.

Sharma P.U. (2013). Bacteriological analysis of street vended fruit juices in Vidharbha. International Journal of Current Microbiology and Applied Sciences, 2(5): 178-183.

Tambekar D.H., Jaiswal V.J., Dhanorkar D.V., Gulhane P.B and Dudhane M.N. (2009). Microbial quality and safety of street vended fruit juices: A case study of Amravati city. Internet Journal of Food Safety, 10: 72-76.

Titarmare A., Dabholkar D.V. and Godbole S. (2009). Bacteriological analysis of street vended fresh Fruit and vegetable juices in Nagpur City, India. Internet Journal of Food Safety, 11: 1-3 